$8-2012$

\title{
Lagging Behind: The Current State of Females in Physics
}

Elisabeth A. Myers

Cedarville University

Follow this and additional works at: http://digitalcommons.cedarville.edu/education_theses

Part of the Gender and Sexuality Commons, and the Science and Mathematics Education Commons

\section{Recommended Citation}

Myers, Elisabeth A., "Lagging Behind: The Current State of Females in Physics" (2012). Master of Education Research Theses. 51. http://digitalcommons.cedarville.edu/education_theses/51

This Thesis is brought to you for free and open access by DigitalCommons@Cedarville, a service of the Centennial Library. It has been accepted for inclusion in Master of Education Research Theses by an authorized administrator of DigitalCommons@Cedarville. For more information, please contact digitalcommons@cedarville.edu. 


\section{LAGGING BEHIND:}

\section{THE CURRENT STATE OF FEMALES IN PHYSICS}

A research project submitted in partial fulfillment of the requirements for the degree of

Masters of Education

By

Elisabeth Ann Myers

B.A. Biology, Cedarville College, 1985

2012

Cedarville University 
LAGGING BEHIND

CEDARVILLE UNIVERSITY

SCHOOL OF GRADUATE STUDIES

August, 2012

I HEREBY RECOMMEND THAT THE RESEARCH PROJECT UNDER MY SUPERVISION BY Elisabeth Ann Myers ENTITLED Lagging Behind: The Current State of Females in Physics BE ACCEPTED IN PARTIAL FULFILLMENT OF THE REQUIREMENTS FOR THE DEGREE OF Master of Education.

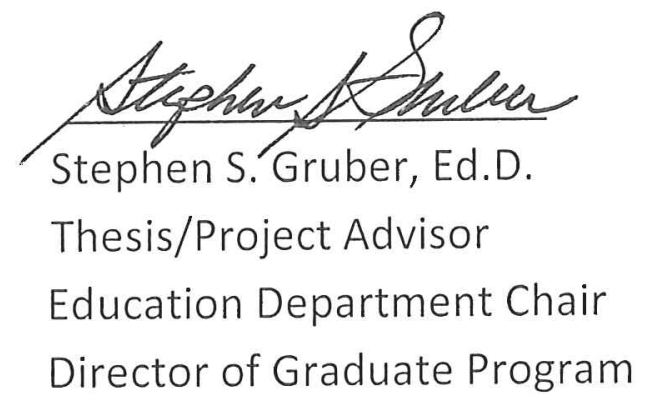

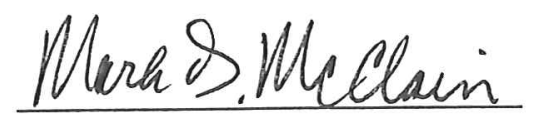

Mark D. McClain, Ph.D. AAVP, College of Professions

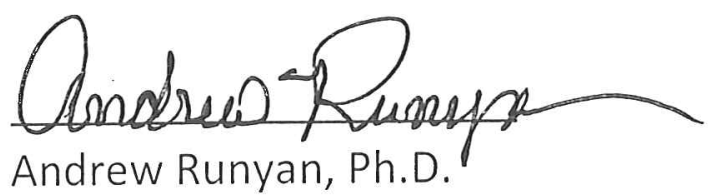

Dean, Graduate Studies 


\title{
LAGGING BEHIND
}

\begin{abstract}
Myers, Elisabeth A. M.Ed., Education Department, Cedarville University, 2011. Lagging Behind: The Current State of Females in Physics.

This qualitative study will provide insight into the lack of interest of female high school students in the field of physics. After participating in the GCCS Science Challenge Day, high school juniors will be surveyed as to their potential interest in the different STEM fields, particularly physics. Themes will be identified from evaluating their experiences. Data from the survey will be used to design an enhanced science curriculum, with the goal of motivating more students in general, and females in particular, to major in physics.
\end{abstract}




\section{LAGGING BEHIND}

\section{TABLE OF CONTENTS}

CHAPTER I: Introduction........................................................

Definition of Terms..................................................... 9

Statement of Issue..................................................

Scope of Study and Delimitations...................................... 10

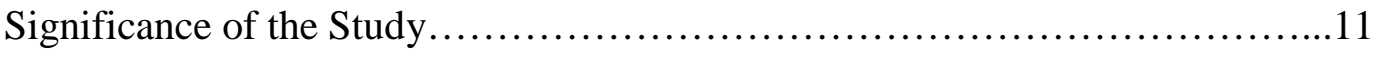

Methods of Procedure..................................................12

CHAPTER II: Plenary Literature Review.....................................14

The Current Situation.................................................14

The Stereotype: Boys Are Naturally Better at Math and, Therefore, Physics......15

The Lack of Interest.................................................20

The Environment: Female and Family Unfriendly........................29

Need for the Present Study............................................ 36

CHAPTER III: Methodology..............................................38

Rationale for the Method...............................................38

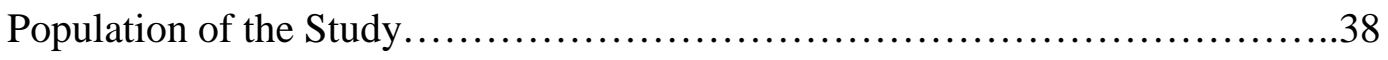

Sample.............................................................. 39

Procedure........................................................... 39

CHAPTER IV: Results: Convenience Sampling.................................41

Overview............................................................41

Confidence in Ability...............................................4

Interest in Pursuing Major.............................................42 


\section{LAGGING BEHIND}

Lack of Interest Comments.............................................43

Other Science Experiences..............................................43

Increase Interest Comments...........................................44

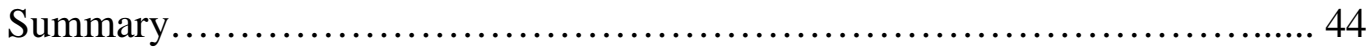

CHAPTER V: Discussion and Implications...................................45

Interpretation of the Results.........................................45

Potential Applications of the Findings..................................47

Biblical Integration.................................................47

Relation of the Results to Literature....................................49

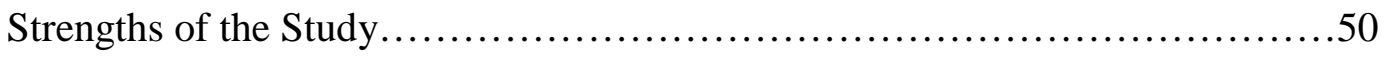

Limitations of the Study...............................................50

Suggestions for Future Research.....................................50

REFERENCES.......................................................... 51

APPENDICES...........................................................60

APPENDIX A: Parental Consent Form.................................60

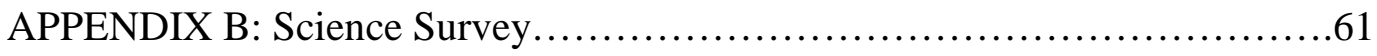

APPENDIX C: GCCS Science Challenge Day $2011 \ldots \ldots \ldots \ldots \ldots \ldots \ldots \ldots \ldots . \ldots 62$ 


\section{LAGGING BEHIND}

\section{Chapter 1: \\ Introduction}

The current state of females in physics is one of lagging behind the participation of women in other science fields. Approximately half of high school physics students are girls. This statistic would lead one to expect a similar engagement at the college level, but, sadly, this is not so. According to data from the National Science Foundation, in 2009 only 19\% of bachelor's degrees awarded in physics went to women. This number was down slightly from a high of $22 \%$ in 2004 . In 2009, $22 \%$ of the master's degrees were awarded to women, down from a high of $25 \%$ in 2004. Eighteen percent of the doctoral degrees awarded in 2009 were earned by women (NSF, 2012). While this number is low, it represents an improvement over 1994, when just over $11 \%$ of the doctoral degrees were being awarded to women (Budilet al., 2005). It also demonstrates a significant improvement from 1972, when only $7 \%$ of the bachelor's degrees and 3\% of the doctoral degrees were being awarded to women (Ivie and Ray, 2005).

In the biological and agricultural sciences, women now earn $60 \%$ of the degrees. A majority of the chemistry degrees also are reported to be earned by women. In the area of mathematics, just under $50 \%$ of the degrees are earned by women. Many women are pursuing and attaining advanced degrees. Almost half of the doctoral degrees in biology and approximately one-third of the doctoral degrees in chemistry and the earth sciences are awarded to women (Jacoby, 2010). Engineering is the one field in which women are an even smaller portion of the degree earners than physics, comprising $16 \%$ of total degree earners (MIT Women’s Initiative, 2010). 


\section{LAGGING BEHIND}

The disconnect for girls begins to show itself while in high school. Although an equal proportion of both male and female high school students are taking physics, girls are not as likely as boys to take AP physics. For example, in 2004 only 25\% of those students taking the calculus-based AP physics exam in mechanics were female. The percentage of algebra-based physics test takers for the same year was higher; 35\% were female (College Board, 2005). This number would seem to indicate a lack of confidence by girls in their ability to handle the additional challenge of an AP course or simply a lack of interest on their part.

Some might think that this subject is just another exaggerated issue being promoted by frustrated feminists. Here we go again, making a mountain out of a mole hill. The reality is that the subject is a matter of national economic health. America is competing on a global economic playing field. Why should we limit ourselves to the resources of only half of our adult population? According to the Science and Engineering Equal Opportunities Act, Section 32(b) passed in December of 1980:

It is the policy of the United States to encourage men and women, equally, of all ethnic, racial, and economic backgrounds to acquire skills in science, engineering and mathematics, to have equal opportunity in education, training, and employment in scientific and engineering fields, and thereby to promote scientific and engineering literacy and the full use of the human resources of the Nation in science and engineering.

We are not doing so well representing minorities among our physics degree earners either. In the class of 2007, only 3\% of the bachelor's degrees earned were awarded to African-Americans of either gender, and another 3\% were awarded to 


\section{LAGGING BEHIND}

Hispanic-Americans of either gender (Mulvey and Nicholson, 2010). Between 1997 and 2003, an average of just under three doctoral degrees were awarded per year to AfricanAmerican women and just under three were awarded to Hispanic-American women. This percentage is out of an average of 1100 doctoral degrees awarded per year (Ivie and Ray, 2005). America is hardly measuring up to "the full use of human resources of the Nation in science and engineering” (The Science and Engineering Equal Opportunities Act, 1980).

How can we reach our full potential in the development of physicists and encourage more women of all ethnicities to pursue a degree in physics? We need to identify the factors that discourage women from this pursuit-- whether they be social, environmental or cognitive--and seek to correct them. We need to examine several tough questions to uncover what is hindering women from seeking advanced degrees in physics: Is the old stereotype that boys are just naturally better in math and science still alive and well? Are physics departments still the good ol' boy clubs of the 1950s where it is hard for women to fit in and even harder for them to advance?

Historically, boys have tested better than girls in math; and since math and science are closely related, particularly in the field of physics, it has been engrained into our national psyche that math and science are just something in which boys excel. They belong there.

However, a recent study that was conducted using data from standardized assessments from ten different states has shown there is no longer any significant difference in the performance of girls and boys on tests of math skills, not even in more complex, problem solving skills, from grades two through eleven (Hyde et al., 2008). 


\section{LAGGING BEHIND}

This information needs to be delivered repeatedly to parents, teachers, and students across America. When given opportunity and instruction, girls are just as good at math as boys are.

An interesting conundrum presents itself when one studies the results of the Nation's Report Card 2005. Female graduates have surpassed male graduates in the number of credits earned in math and science courses. Females had higher combined GPAs in mathematics and science. However, males scored higher in math and science on the NAEP by four points in each area (Shettle et al., 2007). These results lead one to wonder if the females lack knowledge and ability or if the test favors males over females.

Have we been judging math ability based on test-taking ability instead of on actual skills to do the math and to solve problems? Are we overemphasizing test scores and letting them communicate the wrong message to our girls? Are females just as capable as boys when it comes to math and science, but we are making it harder for them to think so? A growing amount of evidence argues that a student who thinks math and science abilities are innate, or are fixed traits, is at a disadvantage when compared to a student who thinks their abilities can be developed. These two differing points of view have been labeled a fixed mindset versus a growth mindset. Some research suggests these mindsets can play an important role in the underachievement/under-involvement of women in math and science. Women with a fixed mindset are much more susceptible to negative stereotypes about the ability of women to do math and science, whereas those with a growth mindset are much more likely to persist and succeed (Dweck, 2008).

It is a widely-held belief that those getting into careers in engineering, math, computer science, or physical sciences are limited to individuals who have ability 


\section{LAGGING BEHIND}

measured in the top few percentiles as measured by high school mathematics test scores. It is such a widely held belief that, according to Catherine Weinberger (2005), no true testing of this assumption has ever been published. According to her study, while many participants in these fields do have exceptional test scores, many do not. They actually come from throughout the upper $40 \%$ of the mathematics test score distribution (Weinberger, 2005).

Fewer than one-third of college-educated white men working in STEM occupations had high school SAT-M scores higher than 650 (out of 800). More than onethird had SAT-M scores lower than 550 which is the $76^{\text {th }}$ percentile of all white men and is the math score of the typical humanities major (Weinberger, 2005). Knowing that exceptionally high math scores are not a requirement for success could open a lot more women's minds to the possibility of physics as a very viable career path.

Another factor working against women feeling confident enough to pursue a career in physics is that women tend to be harder on themselves than men are on themselves. When a woman thinks that “most people” expect men to be more competent at a task, even if she does not hold to this stereotype, she will tend to rate herself as performing lower at the task even if she is performing equally as well, due to the bias created by others' expectations. Men, on the other hand, due to the expectation, are judged by a more lenient standard. Males tend to overestimate their abilities, and women tend to underestimate their abilities (Correll, 2001). This more stringent self-analysis causes many women to second guess their abilities to compete in the field of physics.

One legitimate area of cognitive concern is that of spatial skills, the ability to picture objects in three dimensions. This 3-D visualization ability has been strongly 


\section{LAGGING BEHIND}

linked to gender differences (Sorby, 2009), and it is the females who come out on the short end of the stick. This link has a serious cause for concern with engineering students, but there is also application in the other sciences. The good news is that spatial skills can be improved through practice. Special courses have been designed to do improve spatial skills at the college level and have been studied even at the middle school and high school level (Sorby, 2009). This practice of spatial skills could easily become a required part of a high school geometry course.

Rather than a lack of ability or lack of confidence in their abilities, the poor female enrollment in physics majors might simply be due to a lack of interest. Women may find it hard to picture themselves doing physics for the rest of their lives. This inability to picture a future in physics could be due to a lack of role models in physics careers, a lack of a female-friendly culture, a lack of seeing females teaching physics at both the high school and college level, or a lack of a family-friendly work environment. Even after an initial interest in physics at the college level, some females might not feel like they fit in to the physics culture. Some may not want to become a part of the typical science geek stereotype. Physics may not have an appealing enough image and, after all, image is everything. In addition to preparing girls for physics, we may need to prepare physics for girls.

A study was done comparing five physics departments that graduate a high percentage of female physics majors with four departments that are typical of the percentage of female physics majors who graduate. The following characteristics were found in the high percentage programs. They provided a student lounge where students could study together, tutor others, and interact socially and where faculty interact casually 


\section{LAGGING BEHIND}

with students. A tutorial service is offered, benefitting both the upper level students who are doing the tutoring as well as the struggling students. Student lab assistants are used, providing the physics majors with beneficial experience in setting up lab equipment.

Departmental seminars are scheduled, focusing on career or postgraduate opportunities. Physics clubs were formed to sponsor activities and to provide opportunities for socializing (Whitten et al., 2003). These practices would benefit all physics students, not just the female student.

Other behaviors that also helped to create a female-friendly department were noted in this study. These include the following: Be aware of the student culture to make sure there is an absence of sexist and racist remarks and behavior in the lab or classroom. Emphasize a cooperative rather than competitive atmosphere. Mention female and minority scientists as well as white male scientists. Apply physics to social and environmental issues. Foster student-faculty research to encourage less formal relationships with professors. Promote the safety of students who are working in departments alone or at night (Whitten et al., 2003). These behaviors would also benefit all physics students, not just the female students.

College student demographics have changed quite noticeably in the last 30 years. There are more women, more African-Americans, more Hispanics, and more Asians in the student body. Unfortunately, college professor demographics have not changed. Overall, $87 \%$ of the full-time faculty members in the United States are white; $64 \%$ are male. In science and engineering, the numbers are even more unbalanced: $94 \%$ of full professors are white; and $90 \%$ are male. These numbers are especially troubling when one considers that the most accurate predictor of success for female undergraduates is the 


\section{LAGGING BEHIND}

percentage of women among the faculty members at the college they attend (Trower and Chait, 2002).

A contributing factor to the lack of women in full professorships may be the stress of the tenure process. The timing of the tenure timeline clashes severely with that of starting a family (Trower and Chait, 2002). The acceptability of temporary suspensions in the probationary period (federally mandated maternity leave) during pregnancy may technically be allowed, but is it really acceptable? Does it lead to equal consideration? The demands of research and lab work for science professors are very difficult to balance with family even after tenure is granted. All of these considerations may negate very capable women from choosing this career path.

The percentage of high school teachers who are female is higher than the percentage of female teachers at the college level. In 2009, 32\% of physics teachers were female. This number is an increase of about $10 \%$ over the last 20 years. This increase sounds good in comparison to the college professor scenario, but not as good when you realize that approximately $60 \%$ of high school teachers in the U.S. are women (White and Tesfaye, 2010). Hopefully, the trend will continue and more women will continue to be added to the physics faculty and, thereby, will influence more girls to consider physics an appropriate, achievable career path for women.

An additional burden that women have to bear upon entering a male-dominated field such as physics is that they will tend to be viewed as either competent or likable, but rarely as both. Once women are acknowledged as successful, they will typically be socially rejected. This rejection has been shown to affect job evaluations and recommendations for increases in salary or positions (Heilman et al., 2004). This effect 


\section{LAGGING BEHIND}

would obviously result in frustration and women seeking other career opportunities. Why put up with the hassle?

\section{Definition of Terms}

AP physics/AP course- This refers to an advanced placement course taken for college credit while in high school (College Board, 2005).

NAEP- This refers to the National Assessment of Educational Progress, which is mandated by the U.S. Congress and sponsored by the U.S. Department of Education. The National Center for Education Statistics, a department within the Institute of Education Sciences, administers the test (Shettle et al., 2007).

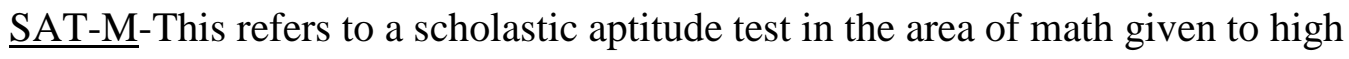
school students. It is the most widely-used college entrance exam. (College Board, 2005).

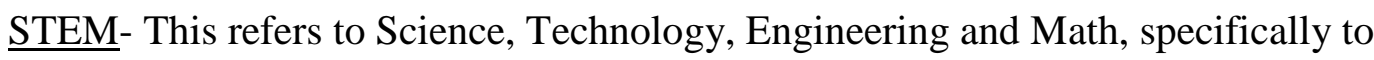
the physical, biological, and agricultural sciences; computer and information sciences; engineering and engineering technologies; and mathematics. It does not include social and behavioral sciences, such as psychology and economics, nor to health fields, such as medicine and nursing (Hill, Corbett, \& St. Rose, 2010).

\section{Statement of Issue}

Although the number of women in science is growing, men continue to outnumber women, particularly in the areas of physics and engineering. Girls and boys take math and science courses in approximately equal numbers throughout middle and high school. About as many girls as boys leave high school prepared to major in physics 


\section{LAGGING BEHIND}

in college. However, the reality is that women are much less likely to pursue a major in physics. Less than $25 \%$ of the physics degrees awarded will go to women.

The factors that cause this disconnect between high school and college need to be discovered and countered if we as a culture are to perform up to our full potential in this technological age. Academic research on this topic is not lacking. Three basic themes emerge as to why there are so few women in STEM fields, particularly in physics and engineering. The first theme is the notion that men are just naturally better at math and science. The second theme is based on an apparent lack of interest by women in physics and engineering. The third theme is centered on the workplace and potential for growth in the career and balancing the demands of raising a family (Hill, Corbett, \& St. Rose, 2010).

This study will center on the second of the three themes. Increasing the interest of girls and women in the field of physics must be prioritized. To do this, we must examine the social, environmental, and cognitive aspects affecting why so few women are pursuing a degree in physics. Then we must deliberately plan, educate, and recruit girls and women to take on the challenge. We also need to challenge the field of physics to take on the women.

\section{Scope of the Study and Delimitations}

In this study, the high school science department will organize a science day for all students who are juniors that will provide two challenges involving a combination of physics and engineering, hands-on problem solving, design, and testing of the design. The students will sign up in groups of two or three to accomplish these tasks. The specifics of the task will not be released ahead of time. After having participated in these 


\section{LAGGING BEHIND}

activities, students will be surveyed to determine their response to this experience as well as their math and science history and potential future plans. When the compilation of the data from this survey is complete, a homogeneous sample selection focus group could be chosen, and a follow-up group interview and discussion could be held if the data warrants further discussion (Johnson and Christensen, 2008). More specific information could be gained using open-ended and targeted follow-up questions.

All juniors will be required to participate regardless of their current science or math class enrollment. Students will be required to work with at least one other person. Students will only be able to use provided materials to build their design project and must work within instructed design parameters. No online or textbook research may be done during the planning and design time. No seeking of help from outside resource people (other teachers) is allowed.

These students are from a private, Christian, charter school. Most of the students are currently enrolled in chemistry or physics and are currently enrolled in Algebra II or have completed the course. The majority of the students have attended this school since at least ninth grade. Only juniors will be allowed to participate.

\section{Significance of the Study}

The number of women pursuing degrees in physics and entering the work force in the field of physics does not reflect the potential of women to do so. In order for America as a country to compete on a global scale, a compilation of the best and brightest of both male and female minds is needed to go into physics and to infuse a fresh perspective on this field. The reasons behind this lack of participation in physics by women needs to be identified. Once identification has occurred, a course of action to 


\section{LAGGING BEHIND}

increase their participation can be mapped out. This plan can then be put into action in our school.

\section{Methods of Procedure}

\section{Research Questions}

1. Do female high school students feel confident in their ability to pursue a physics major in college?

2. What would increase female high school student interest in pursuing a career in physics?

\section{Process}

The main tool used to carry out this qualitative study is a convenience sampling of high school juniors (Johnson and Christenson, 2008). The survey has a demographic section as well as an attitude and future plan section. Before taking the survey, parental consent forms were distributed (see Appendix A). Students were required to turn in the parental permission form in order to receive a survey (see Appendix B). Students indicated their assent to participate by turning in the permission form. Permission forms were distributed during junior science classes or lunch. The permission forms were collected during science classes and lunch.

The survey focused on past classroom experiences in science and math, the recent science day experience, out of school experiences [hobbies, camps, clubs (4H)] and potential future college plans. The surveys were compiled and analyzed to identify themes or concepts. Each student's identity will be kept confidential. No names will be used in discussion or presentation of the data. 


\section{LAGGING BEHIND}

\section{Validity}

In qualitative research, validity is a concept that refers to the credibility and defensibility of the research. One threat to validity is researcher bias, which can be contained by the strategy of reflexivity. Through this strategy, researchers examine themselves and attempt to control their biases by standing outside of their own writing as an objective outside observer (Hellawell,2006). This outside observer mentality must be maintained when answering questions the students may have about the survey and when analyzing the data for themes and concepts. It will also be important to maintain this mindset when conducting the small focus group discussion.

Descriptive validity will be maintained by an accurate compilation of the survey. Interpretive validity will be maintained by seeking participant feedback about any generalized or unclear statements as the compilation is being done. Low inference descriptors (quotations) from the compilation of the data will be used when presenting the themes from the research (Johnson, 1997). Theoretical validity will be maintained by triangulation of data sources from different persons and different classroom experiences, pattern matching, and peer review (Meijer, Verloop, \& Beijard, 2002). The methods by which descriptive, interpretive, and theoretical validity are strengthened all work together to provide internal validity in this study (Johnson, 1997).

External validity is not of great concern in this study as the purpose is to design a program to encourage girls in a small evangelical Christian school to pursue a degree in physics (or other STEM majors). The small sample size and the unique upbringing of many of the students may not allow the results to generalize to all female students in all schools. Random sampling is not feasible in this case. 


\section{LAGGING BEHIND}

\section{Chapter 2: Plenary Literature Review}

The Current Situation

Our culture has come a long way since the early 1970s when only $7 \%$ of the bachelor's degrees and 3\% of the doctoral degrees in physics were being awarded to women (Ivie and Ray, 2005). Currently, the number of women attaining bachelor's degrees in physics is about 20\% (Halpern et al , 2007; NSF, 2012) and the number of doctoral degrees is 18\% (Mulvey \& Nicholson, 2010; NSF 2012). However, these numbers represent a serious lagging behind the participation of women in other science fields. In the biological and agricultural sciences, women are now earning a majority of the bachelor's degrees, about 60\%. A majority of bachelor's degrees is also being obtained by women in the field of chemistry. Even in the supposed nemesis of women, math, just under $50 \%$ of the bachelor's degrees are being awarded to women (Jacoby, 2010). The only other major field in science that is less pursued by women is engineering, in which only 16\% of the bachelor's degrees being awarded are going to women (MIT Women’s Initiative, 2010).

Current research on why women are so outnumbered in physics and engineering has identified three interwoven themes to explain this enigma. The first of these themes is the stereotype that men are just naturally better at math and science. The second of these themes is that women are not interested in physics and engineering. The third of these themes revolves around the female and family unfriendliness of the physics and engineering workplace and pursuit of career (Hill, Corbett, \& St. Rose, 2010). 


\section{LAGGING BEHIND}

\section{The Stereotype: Boys Are Naturally Better at Math and, Therefore, Physics}

Historically, boys have tested better in mathematics than girls, particularly in the area of mathematical reasoning. This claim was purported even among gifted male and female students (Benbow \& Stanley, 1980). This persistent conclusion might lead one to assume girls do not have the math skills required to compete with males in the field of physics and would explain why females are lagging behind in the number of women who are pursuing and attaining a college degree in physics.

Recent studies have concluded that girls have closed the gap in tests of math skills in the United States (Hyde et al., 2008). A cross-national meta-analysis of gender differences in mathematics provided further support to the argument that currently males and females differ very little in mathematics achievement. In this study, the students being tested were between the ages of 14 and 16. They came from 69 different nations and participated in either the Trends in International Mathematics and Science Study (TIMMS) assessment in 2003 or the Programme for International Student Assessment (PISA) assessment also in 2003. The data from 493,495 students was analyzed, and the only significant areas of difference found were males' self-confidence in regard to their

math ability was higher, and males did have a slight advantage in the content domains of Space/Shape on the PISA (Else-Quest, Hyde, \& Linn, 2010).

The National Assessment of Educational Progress (NAEP) also supports the closing of the gap between males and females in tests of math skills. Coley (2001) reported that in 1992 and 1996 white fourth-grade males scored higher in mathematics than white female fourth-graders, but for all racial/ethnic groups, any gender differences in eighth and twelfth grade had disappeared by 1996. However, the same report 


\section{LAGGING BEHIND}

acknowledged that among college-bound seniors, males in all racial/ethnic groups scored higher than females in their groups on the SAT I Mathematics Test. Interestingly, black college-bound seniors were the only group where females scored higher than males on the SAT I Verbal Test. There is not a simple pattern of male or female advantage, and a great degree of similarity actually exists between the sexes. In some specific areas, males are outperforming females; and in other specific areas, females are outperforming males. It is a very complex issue (Coley 2001).

According to a report from the AIP Statistical Research Center on the results from the 2008-09 Nationwide Survey of High School Physics Teachers, the number of girls taking physics in US high schools increased 161\% between 1987 and 2009 (White and Tesfaye, 2011). The number of boys taking physics increased 88\% during the same time frame. Overall, about $47 \%$ of high school physics students are female. The difference is in the number of girls who are taking AP Physics classes. In AP Physics B classes, 41\% of the students are female; while in AP Physics C (mechanics only), 32\% are female. A distinct difference also exists in the proportion of female and male students taking the AP exams. In AP Physics B classes, 50\% of enrolled females choose to take the exam versus $65 \%$ of the enrolled males. In AP Physics C classes, 61\% of enrolled females choose to take the exam versus $78 \%$ of the enrolled males. The hypothesis that mathematical rigor could explain the low representation of females in AP Physics is contradicted by the data that almost half of the students taking the AP Calculus exam were female, and over half of the students taking the AP Statistics exam were female. More male test takers pass AP exams than females (62\% to 55\%) with the exception of art, certain languages, and computer science (White and Tesfaye, 2011). The reasons for this lower participation in 


\section{LAGGING BEHIND}

advanced physics courses and exam taking and performance are not clear. Is it curriculum, culture, stereotypic threat, or something else?

The performance difference on the SAT between males and females does not mean males are necessarily more capable in math. Researchers have found that SAT math scores under-predict female performance in college math courses and over-predict male performance in college courses (Wainer and Steinberg, 1992). This finding would indicate it is not a lack of ability that is causing the lack of female physics majors.

A continuing study of mathematically precocious youth after 35 years indicates it is more than quantitative reasoning ability that leads to achievement in STEM areas. Many females who were identified early on, by age 13, as having more than enough ability in math to succeed in a mathematically demanding field such as physics or engineering were not buying into the program. They were choosing to pursue other advanced degrees. Achievement in math and science careers also relies upon spatial ability, a consideration of verbal ability, preferences as to working with people versus working with things, and the amount of time one is willing to devote to one's career (Lubinski \& Benbow, 2006).

Spelke (2005) addressed the issue of men and women having equal cognitive capacity for math and science careers. She argued adamantly that females indeed do have equal cognitive capacity, and ability is not the reason males dominate the faculties of U.S. universities in the fields of mathematics, engineering, and science. Nor is ability the reason males earn more degrees in the fields of physics and engineering. Her critical review acknowledged that males and females may use slightly different strategies when performing complex mathematical tasks, but they show an equal performance ability on 


\section{LAGGING BEHIND}

core tasks. She particularly questioned using the SAT-M scores as a true assessment of mathematical aptitude, particularly when comparing males and females. Spelke (2005) suggested the gender imbalance present in certain areas of science today may have more in common with the social causes of disparities in the past. Disparities such as those which existed in the fields of medicine or economics may be to blame. She suggested there may be other issues of human biology, but the male domination of STEM fields should definitely not be attributed to cognitive ability (Spelke, 2005).

Weinberger (2005) contended that it is not just individuals who have ability measured in the top few percentiles of mathematical test scores who are working in STEM occupations. She found that while many of those working in STEM occupations do have exceptional test scores, many others do not. Fewer than one-third of collegeeducated white men working in STEM occupations had high school SAT-M scores higher than 650 (out of 800). More than one-third had SAT-M scores lower than 550 which is the $76^{\text {th }}$ percentile of all white men and the equivalent of a math score for the typical humanities major (Weinberger, 2005). It is not just the cream of the crop pursuing and achieving careers in STEM fields.

Halpern et al. (2007) stated that sex differences in science and math achievement are very complex and challenging to explain. There is no simple answer; a wide range of sociocultural forces, as well as brain structure and cognitive abilities, contribute to these differences. As far as the cognitive is concerned, sex differences in math achievement and ability are less distinct in the mid-range of the ability distribution and are more observable in the higher end of the ability/achievement range. Generally, males and females develop early cognitive skills relating to quantitative processing and knowledge 


\section{LAGGING BEHIND}

of objects in the environment equally well. However, by the end of grade school and beyond, females exhibit better verbal abilities and perform better on assessments that include writing and language usage skills. Males do better with the measurement of visuospatial abilities than females and, in general, show more variability in quantitative abilities, meaning there are more males who score higher than females on the quantitative portions of assessments but also more males who score much lower. Female profiles with high ability tend to display more balance between mathematical and verbal abilities, and this leads them to choose careers in mathematics, engineering, or physical-sciences less frequently than males with high ability. It seems they are choosing careers that match what they are best at, a blend of abilities, rather than choosing a field that utilizes only part of their abilities (Halpern et al., 2007).

A study led by researchers at University of Colorado at Boulder found the gap between numbers of women versus men enrolled in college introductory physics courses, and the average better performance of men in these courses is not a result of differences in ability but rather differential preparation prior to college and psychological factors (Hart, 2010). Interestingly, Hart (2010) found that the psychological factors could be overcome with a short writing exercise focusing on important values. This value affirming writing exercise was found to raise women's course grades from the “C” range to the " $\mathrm{B}$ " range and to increase their conceptual mastery of the course material. The research showed that affirming people’s self integrity buffered them from other threats (stereotypic or identity). The writing exercise had no significant effect on the men in the introductory physics course (Hart, 2010). 


\section{LAGGING BEHIND}

Geary et al. (2000) suggested that complex three-dimensional spatial competencies are more of a learned skill for many females, but for males it is more of an inherent skill. This is based on the finding that the relation between IQ and performance on the Mental Rotation Test (MRT) was stronger in females than in males. He attributed the source of the small to moderate male advantage in solving mathematical word problems to computational fluency and spatial cognition (Geary et al., 2000).

This advantage in spatial cognition by males needs to be countered with specific educational opportunities for females to improve their visuospatial skills. Sanchez and Wiley (2010) purported doing this by supporting scientific learning with visualizations that are animated. They completed a study using 96 psychology undergraduates. When animations were used with the presentation of the physical science material, the differences in learning outcomes between males and females were eliminated. Interest in the physical science topic was also much higher among males than females when the material was presented non-illustrated or using static illustrations, but there was no difference in interest in the material when presented with animations. They suggested that supporting early learning in science with animated visualizations would cause females to experience science achievement equivalent to that which males experience. This positive experience could increase female interest in science and could increase the desire of females to pursue degrees in science (Sanchez \& Wiley, 2010).

\section{The Lack of Interest}

Some research indicated that having a fixed mindset versus a growth mindset contributes to the underachievement of women in math and science. A person with a fixed mindset thinks that math and science ability are innate, or a fixed trait. A person 


\section{LAGGING BEHIND}

with a growth mindset thinks that one's abilities can be developed. Women with a fixed mindset are much more likely to agree with the negative stereotypes about the ability of

women to perform well in math and science and would assume they will not succeed and, therefore, they do not even try. Whereas, women with a growth mindset are more likely to try, persist, and succeed (Dweck, 2008).

The Institute of Educational Sciences developed a practice guide for teachers to help them encourage girls in math and science (Halpern et al., 2007). In this guide, they stated that researchers have found females to be less confident in their math abilities than males, particularly as they move into middle and high school and beyond. This belief about their ability shapes their interest and performance in different subjects, the classes they choose to take, extra-curricular activities in which they participate, and the career choices they make. Therefore, if girls’ beliefs about their abilities can be improved, more women would be more likely to participate and perform well in elective, upper-level math and science courses, which would lead to more women pursuing math and science college majors and careers (Halpern et al., 2007).

After 35 years of studying the psychological and social factors influencing course enrollment, college major selection, and career choice, Eccles (2007) hypothesized that the gender differences in participation in physical science and engineering would be most influenced by the individuals' expectations for success and the value they place on the various available options (expectancy-value model). She purported that these beliefs would be influenced by multiple factors, such as enjoyment of the required school work related to the major, connection to the individual's long- or short-range goals, and support of this major choice from the individual's parents, counselors, friends, or 


\section{LAGGING BEHIND}

significant others. She and her colleagues found that males will most likely receive more support for developing a strong interest in physical science and engineering from their parents, teachers, and peers than females will receive. In addition, all will see more examples of males engaged in these occupations than females. Accordingly, the likelihood of females considering these occupations is much lower than it is for men (Eccles, 2007).

Correll (2004) stated that individuals form career aspirations based on perceptions of their own competence at career relevant tasks. Men and women's perceptions of their own competence are biased by cultural beliefs about gender. Males rate themselves higher at tasks in which their culture says males will have an advantage, and females rate themselves lower at these tasks, even when they actually score the same. This perception leads to women not choosing certain career paths because they wrongly assess themselves as lacking in competence to perform well in the career, even though in reality they are as competent as the men (Correll, 2004).

Rittmayer and Beier (2008) referred to this low assessment of one's ability to perform a specific task or low self-efficacy by many females as the confidence gap. They purported that self-efficacy influences choice of goals, efforts made to reach those goals, and amount of persistence when the going gets tough. Students with high science selfefficacy set more challenging goals, work harder to accomplish them, and persist longer to complete a task in the face of adversity. This results in more success, which then boosts self-efficacy and reciprocally boosts performance. Self-efficacy also relates to interest and engagement in a subject. Success leads to greater interest and increases the likelihood of participating in that task at a more challenging level in the future. Many 


\section{LAGGING BEHIND}

females lose interest in STEM because of a lack of belief in their capability of attaining their goals (Rittmayer and Beier, 2008).

Zeldin and Pajares (2000) reviewed how people form their self-efficacy by interpreting information from four sources: mastery experience, vicarious experience, verbal persuasions, and physical and emotional states. They performed a qualitative study of fifteen women who were successful in math-related careers and found that these women recalled encouragement from others or encouragement through vicarious experiences as being the primary influences on their mathematics self-efficacy. The study participants consistently recalled experiences involving an influential person, frequently during a critical time, who helped them develop their view of their abilities while this mentor was honing his or her own skills. Another theme developed from the study was that it was important that others believed in them, as well as believing in themselves. Zeldin and Pajares (2000) concluded that women deeply rely on confidence developed from the relationships they experienced while developing their mathematicsrelated skills. This relational efficacy impacted their self-efficacy extensively.

Evans and Diekman (2009) purported that a focus on the difference in men and women’s distant goals may explain why not as many women are interested in physics. The consensus was that women value communal goals (intimacy, affiliation, and altruism) over agency goals (power, achievement, and new experiences or excitement), and men value agency goals over communal goals. This emphasis on communal goals causes females to seek careers other than physical science or engineering, which they do not perceive as serving humanity, caring for others, or working with people (Diekman et al., 2010). This perception problem of engineering, specifically, and the physical 


\section{LAGGING BEHIND}

sciences, in general, was discussed in a study by the National Academy of Engineering in 2008. This study found that students and adults think of engineers as designing and building things, but they do not connect these things with helping or serving people (National Academy of Engineering Committee on Public Understanding of Engineering Messages, 2008). Thus, the lack of interest in physics and engineering may be a huge perception problem.

The good news is some studies have found that female perception of engineering and physics can be changed in spite of the 2003 NSF report that found only $10 \%$ of physicists/astronomers and engineers were women. One study indicates that computerbased anthropomorphic interface agents that appear female, young, and cool can have a positive effect on stereotypes and self-efficacy of female college-age students toward engineering (Rosenberg-Kima et al., 2008). Another study indicates that attitudes toward these fields and performance on related math skills tests could also be improved by computer-based social models that appear female, young, and cool to middle-school students (Plant et al., 2009). Interestingly enough, the female social models were found to have a positive influence on attitudes towards engineering and skills test performance in both males and females at the middle-school level.

In the spring of 2004 a coalition of engineering associations and societies began a national initiative to encourage girls to pursue careers in engineering (NSF, 2005). This initiative was named the Extraordinary Women Engineers Project (EWEP). It was determined the issue was not one of ability or preparation but one of perception. Engineering was not considered a career option by girls and the people influencing those decisions because they did not understand what a career in engineering involves. It was 


\section{LAGGING BEHIND}

not perceived to be a relevant career option. This study found that girls wanted a job that was enjoyable, has a good working environment, makes a difference, and offers a good salary and flexibility. Instead, the message being portrayed by the engineering community was that engineering is a challenging career, and superior math and science abilities are required. The message did not focus on the benefits or rewards of the job. The main recommendation coming from this study was that a fundamental shift in the way engineering is portrayed is needed (NSF, 2005). This portrayal needs to be focused on benefits and rewards and needs to be personalized and informative about the lifestyle of an engineer. This message needs to target high school girls and their teachers and counselors, as well as engineering professionals and college students majoring in engineering. Although this study specifically addressed the field of engineering, there is much in common between the perception of physics and engineering.

Hazari et al. (2010) presented a study exploring how students’ physics identities influence their career choices. This study was based on data from the Persistence Research in Science and Engineering (PRiSE) project, which surveyed college students in English classes about their high school science experience, science attitudes, and background. The study found physics identity to correlate positively with a desire for an intrinsically fulfilling career but negatively with the desire for opportunities to work with others and for personal or family time. This study may not just impact female interest, as statistics from the National Science Board (2006, 2008) indicated the overall participation rate in physics is lagging behind other fields. Between 1983 and 2005, the number of bachelor's degrees awarded in all fields increased by 47\%; the number of bachelor’s degrees awarded in biological science increased by 66\%; but the number of physics 


\section{LAGGING BEHIND}

bachelor's degrees only increased by $11 \%$. This discussion suggested that if the physics community promoted and supported more balanced motivations, physics would be more successful in attracting members of under-represented groups (females and minorities). The study also indicated that females who had discussed the female under-representation in physics in their high school physics class had a stronger physics identity and, therefore, had an increased likelihood of choosing physics as a career. Unlike some other studies, this study found that using examples of female scientists or having female scientists as guest speakers had no significant influence on females’ physics identity. However, the study did conclude that a focus on conceptual understanding and real-world or contextual relevance could improve females’ physics identity.

Jones et al. (2000) presented a study of 437 sixth grade students from five different schools in the southeastern United States. The schools were located in rural, urban, and suburban communities. The study used a survey instrument "Science and Scientists,” which had been developed as part of a much larger international study comparing children's interests, experiences, attitudes, and perceptions of science. One aspect of the survey focused on out-of-school experiences. The survey found that more males than females reported prior experiences with a variety of tools and objects such as rifles, batteries, electric toys, fuses, microscopes, and pulleys. The females reported more experiences with bread-making, observing birds and stars, knitting, sewing, and planting seeds (Jones et al,. 2000). These results support the idea that boys tend to have more experiences in the physical sciences than girls, and girls tend to have more experiences in the biological sciences than boys. The connection could then be made between prior experiences and future interests. 


\section{LAGGING BEHIND}

The study by Jones et al. (2000) also had a specific focus on student interests. Overall, males reported more interest in learning about a variety of topics than females. There were 20 different topics that males reported being more interested in learning about than females in comparison to 6 topics in which females indicated more interest than males. Males reported wanting to learn about planes, cars, computers, light, electricity, radioactivity, new sources of energy, and x-rays more than females. Females reported wanting to learn about rainbows, healthy eating, colors, animal communication, and AIDS more than males. A tendency toward interest in the physical sciences, particularly in areas of applied physics and engineering, was demonstrated for the males and more of an interest in the biological sciences was demonstrated for the females, although there were exceptions (Jones et al., 2000). These results showed significant gender differences in interests, possibly based on prior experiences. One could focus on the lack of interest in physics and engineering by the females, or one could focus on the lack of interest in biology and medicine by the males.

Osborne et al, (2003) reviewed the major literature of the last 20 years about attitudes toward science and its implications. In this review, gender is identified as one of the main factors influencing students’ attitudes toward science. Girls’ attitudes toward school science are significantly less positive than boys' attitudes are, and this difference is greatest for general (physical) science. The most common, current explanation offered for this finding is that as a result of cultural socialization, girls find less opportunity to play with technological devices, to use common measuring instruments, and to observe common scientific phenomena. This lack of experiences in science leads to a lack of understanding of science and contributes to negative attitudes toward science. In 


\section{LAGGING BEHIND}

addition, girls perceive themselves to be better at other subjects and, therefore, not as good at science. Girls also may be at odds with the nature of science, which claims to be value-free and objective rather than valuing human and affective aspects of knowledge. It was also found that pursuing science may be perceived by many girls as too focused and too limiting of their vocational options, producing a specialist rather than a wellrounded, educated person. All of these factors contribute to keeping the pipeline to physics and engineering looking the same as it always has, predominantly male and white.

In conjunction with the Second International Conference of Women in Physics in 2005, a survey was conducted to gather information about women’s educational backgrounds, careers, relationships between work and family, and opinions about physics as a career in general. Ivie and Guo (2006) wrote the report on the results of this survey titled Women Physicists Speak Again. More than 1350 women physicists from more than 70 countries participated in the survey. A majority of the female physicists (60\%) reported choosing physics as their career during secondary school (high school). Some respondents (15\%) chose physics before secondary school. When asked what or who influenced this decision to choose physics as a career, 50\% reported their teachers influenced them. About 25\% reported it was their parents who influenced their decision. Most respondents (85\%) indicated that interest in the subject was the primary influence. One must note that in this part of the survey, respondents could choose more than one answer (Ivie \& Guo, 2006). These statistics emphasize the need for good science teaching during primary and particularly secondary schooling to inspire this interest in physics. 


\section{LAGGING BEHIND}

Trumper (2006) reported on the results of a study on students’ interest in physics at the end of their compulsory schooling (grade 9) in Israel, which was carried out in the framework of the ROSE (Relevance of Science Education) project. The report did not focus heavily on differences between male and female interest; instead, it focused more on general interest in physics by both sexes. The study purported that physics as it is commonly taught does not take into account students' interests and adding topics that interest both boys and girls to the curriculum could potentially resolve some of the lack of interest in physics. There is a need to concentrate on improving students' affective responses so they find personal satisfaction in doing science and will want to continue doing science. This study expressed particular concern about the quality of teaching at the junior high level. The concern is that teachers at this grade level lack expert knowledge and enthusiasm for the subject. The conclusion was drawn that both curricular and behavioral changes need to be made to improve student interest.

\section{The Environment: Female and Family Unfriendly}

Women are outnumbered by men in all sectors of employment for science and engineering (73\% males vs. 27\% females) (NSF, 2007). In business and industry, the gap is a little larger (79\% males vs. 21\% females). In K-12 schools, two-year colleges, junior colleges, and technical institutes, the female employees do outnumber the men and have lower salaries and less prestige. Men in STEM are more likely to outrank women at any given career stage. Data shows that women are concentrated in lower-status positions, such as early tenure-track ranks, non-tenure-track academic positions, and lower-status institutions (NSF, 2007). 


\section{LAGGING BEHIND}

According to Hazari and Potvin (2005), physics has its own culture bias, one which is rigidly bound by masculine tendencies and preferences. This culture bias is communicated in three different ways. The first way is pedagogically, with a narrow view as to what it means to do physics without any individuality allowed in defining it. Secondly, it is communicated academically by what is considered acceptable physics research, mainly through the peer review processes. Thirdly, it is communicated socially, through the structure, interactions, and treatment of people in the field. Physics is very competitive rather than collaborative. Faculty members in the physics community are key in determining who is included or not. Many of them consciously or subconsciously believe that women are just not into physics the way men are due to inherent differences or socialized differences; therefore, they favor men. Physics has not been about inclusivity; rather, it has been more of a process of isolation and development of an elite group. This elitist form of teaching perpetuates itself and discourages females from pursuing the application of their skills to physics (Hazari and Potvin, 2005).

An example of this poor treatment of female physicists would be that of Melissa Franklin, an admittedly aggressive particle physicist who graduated from the University of Toronto and Stanford University in California. She applied for a position as an assistant professor of physics in 1986 at her alma mater, University of Toronto. She was told she was the leading candidate for the job but then was passed over for a male candidate. In 1988, she again applied for the position of assistant professor of physics at University of Toronto but was offered a junior position as a research fellow. This offer was acknowledged to be an insult to her by another University of Toronto professor. He and others intervened on her behalf, and she was offered the assistant professorship. 


\section{LAGGING BEHIND}

After tentatively accepting the position, she was approached by a male member of the physics department who told her she may have gotten the job, but she was second-rate when it came to physics. Subsequently, she turned down the offer, citing a lack of funding in Canada for the research she had been doing on quarks at the Fermilab collider in Illinois as a junior fellow at Harvard. Interestingly, in 1992, there were no females among the fifty or so members of the physics faculty of U of T (Nichols, 1992).

Studies done by Heilman et al. (2004) found that, in general, when women are successful in what is considered a traditional male role, they are less liked and may be socially rejected. This dislike may translate into evaluations that do not result in rewards in their career, such as salary benefits or other job opportunities or advances. This finding may help to explain the previous example of the treatment of Melissa Franklin. Females work extra hard to succeed and then are socially rejected when they do accomplish their goals.

Another female physicist, astronomer Jocelyn Bell Burnell (2004), has described the recognition and advancement of women in astronomy as disappointing. In 1967, as a doctoral student working on quasars, she was investigating a puzzling weak signal, a string of pulses, and discovered the first pulsar. Her adviser, Professor Antony Hewish, and another professor, Martin Ryle, actually received the Nobel Prize in 1974 for that astronomical discovery. She acknowledged that her student status had much to do with that but contends that her gender may have been culpable as well. Burnell pointed out that in December of 2003 only 10\% of the membership of the International Astronomical Union in the United States and the United Kingdom was female. Her view as a woman in the field of physics is that making women more courageous and assertive, more like men, 


\section{LAGGING BEHIND}

is not the right way to move forward. She stated that women should not have to do all of the adapting; rather, it is time for society to move toward women, fully recognizing them for their contributions and achievements (Burnell, 2004).

An editor for a science education journal, Dale Baker (2002), analyzed the history of articles and editorials published for that particular journal in relation to gender and equity in science education. He found little research dealing with gender or equity during the 1970s and early 1980s. When research was done during this time period, the focus was on sex differences or cognitive ability to do science as correlated to gender. He noted that white male performance was the bench mark, if there were differences, then the white male model was the correct one. The research was approached from the perspective of why a woman cannot be more like a man. In the 1990s, the focus shifted to how to use more girl-friendly strategies and gender-fair assessments. The problem of girls with science was still being seen as a problem with the nature of girls; however, a few people were beginning to get the idea that the problem might have more to do with the nature of science (Baker, 2002).

According to Jill Marshall (2008), the number of women doing physics may not be accurate because they are doing physics in non-traditional ways outside academia. They are still using their physics' knowledge and skills but are not being considered in the pipeline. They are going into engineering applications, aerospace applications, weapons applications, the computer gaming industry, or non-researcher teacher roles, such as compiling and maintaining scientific reference catalogs (astronomical reference catalogs), museum directorships, or teaching younger children. She acknowledged that 


\section{LAGGING BEHIND}

for women in academic careers, a non-tenure track may still be the only option for those with plans to raise children (Marshall, 2008).

In 2006, a research project was begun to examine the career paths of women with degrees in science, technology and engineering in the private sector. Hewlett et al. (2008) reported on this project in a paper entitled “The Athena Factor.” Hewlett and her colleagues found that $41 \%$ of the scientists on the lower rungs of corporate career ladders are female. However, the drop-out rate for females is high. Eventually, 52\% of these women will quit their job due to hostile work environments and extreme job pressures. Quitting typically occurs about ten years into their career path. One of the factors that contributes to this high drop-out rate is hostile macho cultures, described as exclusionary and predatory (63\% of women report experiencing sexual harassment). Another factor is isolation, being the lone woman on a team or at a site. A result of these two factors is that many women lack a clear picture of their career path and feel stuck in their career and hesitate to take the risks required to gain rewards. Additionally, the time intensive nature of the job and the global scope make it difficult to raise a family. The report ended with suggested interventions to prevent this female "brain drain” (Hewlett et al., 2008)

This problem of less success for women in science careers is not just an American problem. Ledin et al. (2007) reported for a study done for the European Molecular Biology Organization (EMBO), which found that traditional gender roles in combination with a negative work culture result in a lower success rate for female researchers versus male researchers. Women in Europe hold less than 15\% of the full professorships, even though more than half of the student population is female. Women take on the majority 


\section{LAGGING BEHIND}

of child care responsibility, as demonstrated by the amount of parental leave they use. They also more frequently put their career in second place to their husband's career, moving to meet the demands of his career. These choices result in fewer weekly working hours and more career breaks leading to less publishing and less advancement in their careers. Female scientists reported fewer mentoring opportunities in the workplace and less supervisor support once they did start their family. Their report expressed concern that a large percentage of higher education graduates are not contributing to the economy as a result of the current system (Ledin et al., 2007). This finding indicated a needed change in the way society views the roles of men and women, and actions need to be taken to improve working conditions and support both men and women who want to have families.

Clayton (2011) reported a similar struggle for women in the United Kingdom. During their pre-tenure years, females work in an insecure environment, compete for short-term contracts and limited grant funding, and face the dilemma of a limited time window in which to start a family. Women have trouble seeing how they can do science and have a family. Men do not have the same biological clock pressure and seem to be more willing to work in a competitive environment. Many women lack confidence and hesitate to seek promotion. The men are more willing to risk rejection. There needs to be a way to fix the system, not the women.

In the report written by Ivie and Guo (2006), female physicists report that nothing is so rewarding yet so challenging as a career in physics. An overwhelming majority (86\%) stated they would still choose a physics career if they had to do it all over again. However, a majority (71\%) reported being discouraged by physics. These women 


\section{LAGGING BEHIND}

identified three problem areas: difficulty in finding employment, discrimination within the field, and a heavy workload. One woman from the United States shared the following: "Interaction with colleagues has been the most difficult. I have often felt that I am ignored or discounted when I attempt to initiate collaborations with men” (Ivie and Guo, 2006, p.11). Another woman from Sweden explained: “I always have to justify why I as a woman have chosen physics. Men never get that question” (Ivie and Guo, 2006, p.11). A third woman from Australia stated: “ The main reason [I’ve felt discouraged] is so often you are just made to feel like you shouldn't be there. You have to work twice as hard, do twice as much just to be considered half as qualified” (Ivie and Guo, 2006, p.11). Many women also discussed the need for improvement in child care issues, but the most commonly expressed need for improvement was that of societal attitudes about women in science.

Ivie and Guo (2006) passed along many of the expressions of frustration shared by the women physicists who were surveyed. This experience of a woman from South Africa spoke to the problem of finding employment: "I am a physicist. I love this profession. It is not about money. I make money in my business, but I want to continue with research and satisfy myself with the profession I first loved passionately. I was greatly disappointed when I could not get a permanent job in physics”(Ivie and Guo, 2006, p.10). Addressing both employment and discrimination issues, a woman physicist from France shared, “Sexism is still important in experimental fundamental physics, and the theoretical field is completely closed to women, described as not enough clever or intelligent to [do] such research... this is really what men told me!”(Ivie and Guo, 2006, p.10). A female physicist from India shared, "I have among other things been subjected 


\section{LAGGING BEHIND}

to gender discrimination and harassment. Although I have been vindicated in my appeals against these, it has taken time and energy from my life and career, and a career in physics is not worth such hassle”( Ivie and Guo, 2006, p.11). These are powerful voices; however, these problems are not only occurring in other countries. A woman physicist from the United States shared, “Sometimes chasing one more grant, or trying to do one more experiment with equipment that needs to be replaced, or trying to explain one more time why my colleagues' assessment of a female candidate is biased, seems like too much” (Ivie and Guo, 2006, p.11). These women all testify to the widespread discouragement and discrimination they have experienced in the unfriendly to females field of physics. It is no wonder that the number of women in the field of physics is lagging and that the drop-out rate of mid-career female physicists is so high.

\section{Need for the Present Study}

The ability gap in math has been identified, addressed, and sufficiently improved. Women are pursuing and achieving college degrees in math at an equal rate to men. Women can and are capable of doing the math. This information needs to be emphasized in our schools, spread in our streets and shouted from the rooftops. We need to break down the stereotype that men are better than women at doing math-related tasks.

Women's interest in entering the field of physics is still lagging behind that of men. It is this lack of interest starting at the secondary level and increasing through the college level that needs further study. Most of the research purports that the lag can be explained by a lack of confidence on the part of women and a lack of cultural support for women in this role. The lag may also be attributed to a misperception of the field of physics and the role and importance it plays in our culture. These explanations need to 


\section{LAGGING BEHIND}

be verified by boots on the ground, people who are embedded with these students and who can pick their brains as to why or why not they would consider tackling the field of physics. The identified issues then need to be addressed both in schools and with parental and community support. That will be the focus of this research project as this researcher is embedded with these high school students who are making their career choices.

The high attrition rate of women who have pursued and obtained degrees in physics also needs to be studied further. Are these talented women being offered the same opportunities as men, the same respect as men, and the same workload? Others are beginning to address that part of the problem and are making suggestions as to changes that need to be made. That is not the focus of this study. Physics is a field where we need to encourage both males and females who have ability and interest to pursue it, particularly if America is to compete on a global scale economically and technologically. 


\section{LAGGING BEHIND}

\section{Chapter 3: \\ Methodology}

The method chosen to determine if girls are confident enough to pursue a college degree in physics and if they are interested enough to do so is a convenience sampling of high school juniors. This convenience sampling will take place at the end of a school day set apart as a day to focus on science. The day is called the Junior Science Challenge Day and involves the students participating in two hands-on activities that focus on physics/engineering concepts. A female speaker was also brought in to discuss her career as an ODOT engineer.

\section{Rationale for the Method}

The main tool used to carry out this qualitative study is a convenience sampling of high school juniors. The focus of this study is to determine why girls are not pursuing physics degrees in college. The best way to determine this decision is to ask them directly. Juniors are the focus of this study because many of them are beginning to seriously consider what they want to study in college but have not yet finalized their decisions. The school day chosen for the science challenge and follow-up survey is a day when freshman and sophomore students are out of the building doing career shadowing and the seniors are on a service retreat. The juniors are truly a convenient group to sample.

\section{Population of the Sample}

The students being sampled attend a private, Christian charter school. Most of the students are currently enrolled in Chemistry or Honors Chemistry, with some being in Physics, Honors Physics, or AP Biology. Almost all of the students have attended this 


\section{LAGGING BEHIND}

school at least since the ninth grade. All of the participants are juniors. Most plan on attending college. No minorities are present in this particular group of students.

\section{Sample}

The sample was composed of 19 females and 11 males. Two other students in the population, one male and one female, were absent.

\section{Procedure}

Information sheets and permission slips were distributed to all juniors at lunch approximately one week prior to the science challenge. Students were instructed to return the permission slips to their current science teacher or to the science challenge coordinator. If permission slips were not turned in as of the day before the challenge, students were provided with another permission slip to remind them to submit it on the day of the challenge. Students were required to sign up in groups of two or three to participate. The sign-up sheet was placed outside the Chemistry Lab door. If students did not sign up, they were placed in a group.

On the day of the science challenge, students reported to the Chemistry Lab to begin the day (see Appendix C for the specific schedule and description/instructions). Students participated in an egg drop challenge and then in a vehicle building challenge. The egg drop challenge involved using only provided materials to build a container that would protect an egg from cracking or breaking when dropped from a height of twenty feet. Students were allowed to test their designs from a lesser height and to change the container as needed within the assigned time frame. The vehicle building challenge involved using only provided materials to build a vehicle to race against the other participants. The vehicle could not be touched directly to propel it nor could it be 


\section{LAGGING BEHIND}

launched. Lunch was scheduled between the two activities. The second challenge was followed by a presentation from a female ODOT Engineer about the career of engineering, her educational background, and what she did on the job. After a question and answer time with the female engineer, students finished their day by filling out the survey (see Appendix B). 


\section{Chapter 4: \\ Results of Convenience Sampling}

\section{Overview}

Thirty students participated in the junior science challenge. All 30 participants filled out a survey. One of the 30 surveys was not complete; questions 14 and 15 were left unanswered. This student usually requires extra time to complete assignments and, therefore, may not have had sufficient time to finish the survey.

\section{Confidence in Ability}

Of the 19 female participants, 4 participants expressed confidence in their ability to pursue a major in physics in college. Two of those four have completed a high school physics course. Three of the 19 females surveyed have taken a high school physics course.

Of the 11 male participants, 4 participants expressed confidence in their ability to pursue a major in physics in college. Two of the four have completed a high school physics course. Three of the 11 males surveyed have taken a high school physics course.

Of the 19 female participants, 11 participants expressed confidence in their ability to major in biology; 7 participants expressed confidence in math[ 6 participants expressed confidence in chemistry; 4 participants expressed confidence in physics, and 1 participant expressed confidence in engineering.

Of the 11 male participants, 6 participants expressed confidence in their ability in math; 5 participants expressed confidence in engineering; 4 participants expressed confidence in physics; 2 participants expressed confidence in biology, and 1 participant expressed confidence in chemistry. 


\section{LAGGING BEHIND}

\section{Interest in Pursuing Major}

Of the 4 females who expressed confidence in physics, 2 also expressed an interest in physics. These 2 participants were currently enrolled in a physics class. No female who was not confident in her physics ability expressed an interest in physics; however, one of the females participants who expressed an interested in physics was not confident of her ability in math.

Of the 4 males who were confident in their ability in physics, 3 expressed an interest in physics. Two of these three participants are currently enrolled in physics. One male participant who was not confident in his ability also expressed interest in majoring in physics. He is not currently enrolled in physics but was one of a few who responded that he had participated in hobbies, camps, or clubs that were science related. All 4 of the males who expressed an interest in majoring in physics were also confident of their ability to major in math.

Of the 11 females who expressed confidence in their ability in biology, 9 expressed interest in pursuing biology as a major; additionally, one other non-confident participant expressed interest in the major. Of the 7 who expressed confidence in math, 3 expressed interest in that as a major. Of the 6 expressing confidence in chemistry, 4 expressed interest in that major.

As previously reported, of the 4 who expressed confidence in physics, 2 expressed an interest in that major. One female expressed confidence in engineering, but 2 expressed an interest in that major.

Of the 6 males who expressed confidence in their math ability, all 6 expressed an interest in pursuing that major. Of the 5 males who expressed confidence in their ability 


\section{LAGGING BEHIND}

in engineering, all 5 expressed an interest in that major. As previously reported, of the 4 males who expressed confidence in physics, 3 expressed an interest plus one additional male. Of the 2 males who expressed confidence in their ability in biology, one was interested in that major. In addition, 3 non-confident males expressed an interest in a biology major. One male expressed confidence and interest in chemistry. In addition 3 other males who did not express confidence in chemistry expressed interest in that major.

\section{Lack of Interest Comments}

Survey participants were asked to briefly explain why they were not interested in specific science majors. The female participants responded more frequently than the males responded. In regards to why they were not interested in physics, 6 female participants simply stated that the subject was not interesting; 3 participants stated they do not like physics; 3 participants stated they did not know much about physics/never had the course; 2 participants stated they were not into math; 1 participant said physics was confusing; 1 participant said it was not fun; and 1 participant said she did not have the patience for it.

The male participants who responded to the question about why they were not interested in physics provided the following reasons: not interesting (4 respondents) and no skills (one respondent).

\section{Other Science Experiences}

The survey asked if anyone had participated in hobbies, camps, or clubs that were science related (robotics, $4 \mathrm{H}$, etc.). One female responded that she had participated in 4H. Two of the males responded that they had participated in such activities. One had 


\section{LAGGING BEHIND}

participated in robotics and $4 \mathrm{H}$, and the other had participated in science-related activities through the YMCA Leader’s Club.

Participants were also asked if the Junior Science Challenge day increased their interest in physics or engineering. Three females responded yes, while one responded maybe. Seven males responded yes, and one responded a little.

\section{Increase Interest Comments}

When asked what could be done to increase their interest in physics or engineering, females and males responded similarly. The suggestions included the following: field trips to observe physics/engineering jobs in action, more days like the science challenge days, more hands-on opportunities to experiment, and more basic courses offered in high school.

\section{Summary}

Four of nineteen females expressed confidence in their ability to pursue a major in physics. Two of the nineteen expressed an interest in majoring in physics. Females expressed the most confidence in their ability to do biology and the most interest in pursuing a degree in biology as well. Four of eleven males expressed confidence in their ability to pursue a major in physics. Four of eleven expressed an interest in majoring in physics. One of the four males expressing interest was not confident in his ability to major in physics.

Males expressed the most confidence in their ability to do math and the most interest in pursuing a degree in math as well. However, engineering ran a close second in both categories. Males responded more positively to the science challenge increasing their interest in physics than females responded. 


\section{LAGGING BEHIND}

\section{Chapter 5: \\ Discussion and Implications}

\section{Interpretation of the Results}

Twenty one percent of the females surveyed felt confident in their ability to study physics in college. Thirty-six percent of the males surveyed felt confident in their ability to study physics in college. Both sets of students come from similar academic backgrounds, having taken certain required courses with the exception of physics. Physics is not yet a requirement for graduation, and currently most students take physics in their senior year. Fifteen percent of the females who were surveyed have taken physics, while $27 \%$ of the males have taken physics. It is hard to draw a direct correlation with these numbers due to the small sample size and uneven ratio of females to males in the sample. However, a slightly higher level of confidence in their ability to do physics can be seen in the males.

Of those who expressed confidence in their abilities fifty per cent of the females also expressed interest in majoring in physics, whereas seventy-five percent of the confident males expressed interest and one non-confident male expressed interest in pursuing physics in college. It is interesting to note that both of the females who expressed interest are currently enrolled in a physics class. Two of the four males who expressed interest are currently enrolled in a physics class. Once again, the small sample size needs to be considered; therefore, a higher level of interest in physics can be seen in males, but the difference may not be as significant as it initially sounds.

It is interesting to note the higher level of confidence females feel in biology and chemistry, about three times the level of confidence of males (58\% to $18 \%$ in biology and $31 \%$ to $9 \%$ in chemistry). The males expressed higher confidence in math: $54 \%$ for 


\section{LAGGING BEHIND}

males to $36 \%$ for females. The biggest disparity is seen in comparing confidence in engineering. The males expressed a $45 \%$ rate of confidence versus a $5 \%$ rate of confidence for females. In this population, it is interesting to note that the students have really had very little experience with engineering. The most direct experience would have been with the presentation of the ODOT engineer right before the survey was

presented. It can be seen that females express more confidence in biology and chemistry, whereas the males come out on the side of math and significantly for engineering in this particular population.

The comments explaining the lack of interest in physics seemed centered around a lack of knowledge of and experience with physics. All of the females who were not interested in physics responded to the question. Thirty-five percent simply stated physics was not interesting. Seventeen percent cited not knowing much about physics or not having the class. Seventeen percent stated they did not like physics. Eleven percent were put off by the math aspect of physics. Six percent each claimed physics is confusing or not fun, or a lack of patience on their part. It was the responder with the lack of patience who was the only current female physics student not interested in the subject. The males who responded to explaining their lack of interest in physics were similar to the females. Of the five who responded, $80 \%$ simply stated physics was not interesting, and the other $20 \%$ claimed a lack of skills. The one current male physics student not expressing interest was in with the $80 \%$, although the reason for his lack of interest was stated more as an "I just don’t want to.”

The lack of extracurricular involvement with physics and with science in general is very revealing of American culture and what we value. Only $10 \%$ mentioned 


\section{LAGGING BEHIND}

participation in hobbies, camps, or clubs that were science related. In response to the question about the impact of the science challenge increasing their interest in physics or engineering, $72 \%$ of the males responded positively, whereas only $21 \%$ of the females responded positively. That may reflect on the competitive nature of the challenge.

Observations of the males seemed to indicate a little more intensity focused on the competition aspect. Several of the females expressed frustration when their first designs would not work. They seemed less likely to rebuild/redesign their projects, particularly with the vehicle challenge.

\section{Potential Applications of the Findings}

Requiring physics to be taken in order for students to graduate from high school could increase student confidence in the subject as they have more experiences with the subject. Designing these required physics courses to be very hands-on and applicationoriented to provide positive experiences with the subject matter could increase interest. Offering additional courses in STEM and designing these courses to be very hands-on and practical could increase interest as well. Introducing a math/science/engineering challenge day, such as a roller-coaster building contest, at the middle school level could give a positive experience with physics early on in a students' educational experience. Planning a field trip that all physics students would take, thus exposing them to specific career opportunities in physics, may help to generate interest in the field as well as help students to understand how physics benefits our society.

\section{Biblical Integration}

"In the beginning God created the heaven and the earth" and proceeded to fill it with light, water, dry land, plants, the sun, moon and stars and animals (Gen. 1:1). Then, 


\section{LAGGING BEHIND}

He created man in his own image and gave him a mandate to "be fruitful and multiply, and fill the earth, and subdue it.” (Gen. 1:28) A little later on, the author writes that God put man into the Garden of Eden “to cultivate it and keep it.” (Gen. 2:15) This filling of the earth, subduing of it, and keeping of it involves learning about creation and how to manage it, gaining knowledge of it, using it wisely, and preserving it for continued use of its resources. The role of education is to make us better stewards of God's creation and to increase our knowledge of our creator as we understand His creation.

Physics is all about understanding God's created world and determining how it works and how everything is interrelated. Scripture sheds light on the four fundamental forces identified by physicists: the strong nuclear force, the weak nuclear force, electromagnetism, and gravity. In Colossians 1:16-17, Paul stated that Christ is before all things and by Him all things consist. The Greek verb for consist (sunistao) means to cohere, preserve, or hold together (DeYoung, 2000). DeYoung (2000) points out that this word as it is used in Colossians is in the perfect tense, implying a present continuing state arising from a completed past action. This word is very descriptive of gravity and the other forces. If gravity were to cease, or even just be temporarily interrupted, our universe as we know it would no longer hold together. The same could be said for the strong nuclear force holding the nuclei of atoms together or electromagnetism holding molecules together if they were to stop working even temporarily. These forces all work together to hold our world together as it was designed to function.

Hebrews 1:2-3 state that Christ upholds all things by the word of His power. DeYoung (2000) explains that uphold (phero) describes the sustaining and maintaining of all things and means more than simply supporting a weight; it includes control of all 


\section{LAGGING BEHIND}

the ongoing motions and changes within the universe. The word of His divine power is manifested through the four fundamental forces and results in the world functioning as it does today.

Understanding the physics of creation, the complexity of it all and yet the unity of how it functions should declare the awesomeness of God's intellect and power. Physics is a worthy pursuit, and this pursuit of knowledge should be encouraged equally among males and females. Both males and females should strive to be worthy stewards. Both females and males are of equal value and worth to God, and both were designed to contribute to our culture.

\section{Relation of the Results to the Literature}

The female respondents' much higher rate of interest in biology and chemistry fits with the patterns recorded in the literature. The numbers interested in math are not as even as the literature would indicate they should be. The drop off in interest in physics is not as severe as the literature would indicate, but the responses still demonstrate a decline. The lack of female interest in engineering indicated by the survey was a bit more extreme than the literature indicated and what the literature indicated was already extreme.

The role that confidence in ability plays in determining interest appears to be more significant for females. This finding is consistent with the literature. The overall possession of confidence for engineering and interest in engineering for the males seemed very high for the lack of real background experience with the subject. This would also be supported by the claims in the literature that males tend to be much more confident and girls tend to underestimate their abilities. 


\section{LAGGING BEHIND}

\section{Strengths of the Study}

The major strength of this study is that the voices of the students are being heard. The students, both male and female, were provided with experiences and were asked to respond to those experiences and relate to past experiences as well. They were asked to think and analyze their future career choices in light of their experiences. This may be a different approach for many of the students. It is also different from much of the literature in that the subject of the discussion is speaking.

\section{Limitations of the Study}

The major weakness of this study is the small number of students in the population. The brevity of some of the responses may be seen as a weakness, but requiring in-depth answers would be a turn off to having the surveys completed. A risk is also present that students may just want to supply answers they think will please the science challenge coordinator. That may be limited in this case by the fact that only four of the students surveyed have the science challenge coordinator as a classroom teacher.

\section{Suggestions for Future Research}

It would be interesting to continue the survey as changes are made to the school curriculum to see if the changes have the desired effect of increasing the interest of females in pursuing physics in college. A female focus group could be formed to discuss interesting comments on the survey or to increase the depth of the responses. All physics students could be surveyed at the end of their high school physics course to see if the interest level of pursuing a physics degree in college has increased. If alumni surveys are conducted, it would be valuable to see how many have pursued various STEM majors in college. 


\section{LAGGING BEHIND}

\section{References}

Baker, D. (2002). Editorial: Where is gender and equity in science education? Journal of Research in Science Teaching 39(8), 659-663.

Benbow, C.P. \& Stanley, J.C. (1980). Sex differences in mathematical ability: Fact or artifact? Science, 210, 1262-1264. Retrieved from http://www.udel.edu/psych/kbauer/benstun.html

Budil, K., Daniels, K.E., Daniels-Race, T., Eblen-Zayas, M., Hartline, B.K., Hazeltine, R... \& Zastavker, Y.V. (2005). Women in physics in the United States: A progress report. Retrieved from http://luxsci.net/zhenga/WomenInPhysics/US_21UPAP_FINAL-New.pdf.

Burnell, S.J. (2004). So few pulsars, so few females. Science, 304(5670), 489.

Clayton, J. (2011, January 21). Fix the system, not the women. Science. Retrieved from http://www.sciencemag.org/

Coley, R.J. (2001). Differences in the gender gap: Comparisons across racial/ethnic groups in education and work. Princeton, N.J.: Educational Testing Service.

College Board. (2005). Advanced Placement summary information. New York: The College Board.

Correll, S.J. (2001, May). Gender and the career choice process: The role of biased selfassessments. American Journal of Sociology,106(6), 1691-1730. Retrieved from http://www.uiowa.edu/ c076150/correll_article.pdf.

---- (2004). Constraints into preferences: Gender, status, and emerging career aspirations. American Sociological Review ,69(1), 93-111. Retrieved from http://soc.washington.edu/users/brines/correll.pdf 


\section{LAGGING BEHIND}

DeYoung, D. (2000, June 1). Gravity: The mystery force. Creation. Retrieved from http://www.answersingenesis.org/articles/cm/v22/n3/gravity

Diekman, A. B., Brown, E.R., Johnston, A.M., \& Clark, E.K. (2010). Seeking congruity between goals and roles: A new look at why women opt out of science, technology, engineering, and mathematics careers. Psychological Science, 21(8), 1051-1057.

Dweck, C.S. (2008). Mindsets and math/science achievement. The Opportunity Equation. Retrieved from http://opportunityequation,org/teaching-and-leadership/mindsetsmath-science-achievement

Eccles, J.S. (2007). Where are all the women? Gender differences in participation in physical science and engineering. In S.J. Ceci \& W.M. Williams (Eds.), Why aren't more women in science? Washington, DC: American Psychological Association. Retrieved from http://www.rcgd.isr.umich.edu/g

Else-Quest, N.M., Hyde, J.S., \& Linn, M.C. (2010). Cross-national patterns of gender differences in mathematics: A meta-analysis. Psychological Bulletin, 136(1), 103127. Retrieved from http://www.apa.org/pubs/journals/releases/bul-136-1-103.pdf

Evans, C.D., \& Diekman, A.B. (2009). On motivated role selection: Gender beliefs, distant goals, and career interest. Psychology of Women Quarterly, 33, 235-249.

Geary, D.C., Saults, S.J., Liu, F., \& Hoard, M.K. (2000). Sex differences in spatial cognition, computational fluency, and arithmetical reasoning. Journal of Experimental Child Psychology, 77, 337-353. Retrieved from http://web.missouri.edu/gearyd/GearySaults2pdf 


\section{LAGGING BEHIND}

Halpern, D.F., Aronson, J., Reimer, N., Simpkins, S., Star, J.R., \& Wentzel, K. (2007). Encouraging girls in math and science (NCER 2007-2003). Washington, DC: U.S. Department of Education, National Center for Education Research. Retrieved from http://ies.ed.gov/ncee/wwc/pdf/practiceguides/20072003.pdf

Halpern, D.F., Benbow, C.P., Geary, D.C., Gur, R.C., Hyde, J.S. \& Gernsbacher, M.A. (2007). The science of sex differences in science and mathematics. Psychological Science in the Public Interest, 8(1), 1-51. Retrieved from http://www.vanderbilt.edu/Peabody/SMPY/ScienceSexDifferences.pdf

Hart, A. (2010, November 26). Can simple writing exercises bring more women into classes in physics? Examiner. Retrieved from http://examiner.com

Hazari, Z. \& Potvin, G. (2005). Views on female under-representation in physics: Retraining women or reinventing physics? Electronic Journal of Science Education, 10(1).

Hazari, Z., Sonnert, G., Sadler, P.M., Shanahan, M. (2010). Connecting high school physics experiences, outcome expectations, physics identity, and physics career choice: A gender study. Journal of Research in Science Teaching, 47(8), 9781003. Retrieved from http://www.clemson.edu

Heilman, M.E., Wallen, A.S., Fuchs, D. \& Tamkins, M.M. (2004). Penalties for success: Reactions to women who succeed at male gender-typed tasks. Journal of Applied Psychology, 89(3), 416-427. Retrieved from http://www.genderinscience.org/downloads/BMS_refences/Heilman\%20adn\%20 Wallen\%202004.pdf 


\section{LAGGING BEHIND}

Hellawell, D. (2006). Inside-out: Analysis of the insider-outsider concept as a heuristic device to develop reflexivity in students doing qualitative research. Teaching in Higher Education, 11, 483-494.

Hewlett, S.A., Luce, C.B., Servon, L.J., Sherbin, L. Shiller, P., Sosnovich, E., \& Sumberg, K. (2008). The Athena factor: Reversing the brain drain in science, engineering and technology (Harvard Business Review Research Report). Boston: Harvard Business Publishing.

Hill, C.H., Corbett, C., \& St. Rose, A. (2010). Why so few? Women in science, technology, engineering, and mathematics. AAUW: Washington, DC.

Hyde, J., Lindberg, S., Linn, M.C., Ellis, A.B., \& Williams, C.C. (2008, July 25). Gender similarities characterize math performance. Science, 321. Retrieved from http://www.sciencemag.org.

Ivie, R. \& Guo, S. (2006). Women physicists speak again. College Park, MD: American Institute of Physics.

Ivie, R., \& Ray, K.N. (2005). Women in physics and astronomy,2005. College Park, MD: American Institute of Physics.

Jacoby, J. (2010, March 28). Good news on women in science. Boston.com. Retrieved from http://boston.com

Johnson, B., \& Christensen, L. (2008). Educational research quantitative, qualitative, and mixed approaches. Thousand Oaks, CA: Sage Publications.

Johnson, R.B. (1997). Examining the validity structure of qualitative research. Education, 118, 282-292. 


\section{LAGGING BEHIND}

Jones, M.G., Howe, A., \& Rua, M.J. (2000). Gender differences in students’ experiences, interests, and attitudes toward science and scientists. Science Education, 84, 180192.

Ledin, A., Bornmann, L., Gannon, F. \& Wallon, G. (2007). A persistent problem. Traditional gender roles hold back female scientists. EMBO Reports, 8(1), 982987. Retrieved from http://www.ncbi.nim.nih/gov/pmc/articles/PMC2247380

Lubinski, D. \& Benbow, C.P. (2006). Study of mathematically precocious youth after 35 years: Uncovering antecedents for the development of math-science expertise. Perspectives on Psychological Science 1(4), 316-345. Retrieved from http://www.vanderbilt.edu/Peabody/SMPY/DoingPsychScience 2006.pdf

Marshall, J.A. (2008). Escape from the pipeline: Women using physics outside academia. The Physics Teacher,46. Retrieved from http://scitation.aip.org

Meijer, P.C., Verloop, N., \& Beijaard, D. (2002). Multi-method triangulation in a qualitative study on teachers’ practical knowledge: An attempt to increase internal validity. Quality \& Quantity, 36,145-167.

MIT Women’s Initiative. (2010, September 12). Women in engineering. Retrieved from http://web.mit.edu/wi/home2shtml.

Mulvey, P., \& Nicholson, S. (2010, January). Physics graduate enrollments and degrees. Focus On. Retrieved from http://www.aip.org/statistics/trends/gradtrends.html.

-----. (2010, January). Physics undergraduate enrollments and degrees. Focus On.

Retrieved from http://www.aip.org/statistics/trends/undergradtrends.html. 


\section{LAGGING BEHIND}

National Academy of Engineering Committee on Public Understanding of Engineering Messages. (2008). Changing the conversation: Messages for improving public understanding of engineering. Washington, D.C.: National Academies Press.

National Science Board. (2006). Science and engineering indicators. National Science Foundation Report, 06-01. Retrieved from http://www.nsf.gov/statistics/seind06/.

National Science Board. (2008). Science and engineering indicators. National Science Foundation Report, 08-01. Retrieved from http://www.nsf.gov/statistics/seind08/.

Nichols, M. (1992). Brain-drained. Maclean’s, 105, 29.

NSF, National Science Foundation, Division of Science Resources Statistics (2007). Women, Minorities, and Persons with Disabilities in Science and Engineering: NSF 07-315. Retrieved from http://www.nsf.gov/statistics/wmpd/employ.htm

NSF, National Science Foundation. (2005). Extraordinary Women engineers final report April 2005. Boston, MA: WGBH.

NSF, National Science Foundation. (2012). Women, minorities, and persons with disabilities in science and engineering. Retrieved from http://www.nsf.gov/statistics/wmpd/.

Osborne, J., Simon, S., \& Collins, S. (2003). Attitudes towards science: A review of the literature and its implications. International Journal of Science Education, 25(9), 1049-1079. Retrieved from http://cset.stanford.edu/research/references/science.

Plant, E.A., Baylor. A.L., Doerr, C.E., \&Rosenberg-Kima, R.B. (2009). Changing middle-school students’ attitudes and performance regarding engineering with computer-based social models. Computers \& Education, 53, 209-215. Retrieved from http://www.elsevier.com/locate/compedu. 


\section{LAGGING BEHIND}

Rittmayer, A.D., \& Beier, M.E. (2008). Overview: Self-Efficacy in STEM. SWE-AWE CASEE Overviews. Retrieved from http://www.AWEonline.org.

Rosenberg-Kima, R.B., Baylor, A.L. Plant, E. A., \& Doerr, C.E. (2008). Interface agents as social models for female students: The effects of agent visual presence and appearance on female students’ attitudes and beliefs. Computers in Human Behavior, 24, 2741-2756. Retrieved June 16, 2012 from http://www.elsevier.com/locate/comphumbeh.

Sanchez, C.A., \& Wiley, J. (2010). Sex differences in science learning: Closing the gap through animations. Learning and Individual Differences, 20, 271-275. Retrieved from http://Litd.psch.uic.edu/personal/jwdey/sanchez_wiley_sex.pdf

Shettle, C., Roey, S., Mordica, J., Perkins, R., Nord, C., Teodorovic, J...\& Kastberg, D. (2007). The nation's report card: America's high school graduates. (NCES 2007467). U.S. Department of Education, National Center for Education Statistics. Washington, DC: U.S. Government Printing Office.

Sorby, S. (2009, February). Educational research in developing 3-D spatial skills for engineering students. International Journal of Science Education, 31(3),459-480. Retrieved fromhttp://www.engageengineering.org/associations/11559/files.Education\%20R esearch\%20in\%20Spatial\%20skills...

Spelke, E.S. (2005). Sex differences in intrinsic aptitude for mathematics and science? American Psychologist, 60(9), 950-958. Retrieved from http://www.wjh.harvard.edu/Ids/pdfs/spelke2005.pdf 


\section{LAGGING BEHIND}

The Science and Engineering Equal Opportunities Act of 1980, 42, U.S.C., 1885, et seq., (1980).

Trower, C.A., \& Chait, R.P. (2002, March-April). Faculty diversity too little for too long. Harvard Magazine. Retrieved from http://www.faculty.diversity.ucla.edu/gendeqwise/docs/030233\%20Harvard\%20 Magazine.pdf.

Trumper, R. (2006). Factors affecting junior high school students’ interest in physics. Journal of Science Education and Technology, 15(1), 47-58.

Wainer, H., \& Steinberg, L.S. (1992). Sex Differences in performance on the mathematics section of the Scholastic Aptitude Test: A bidirectional validity study. Harvard Educational Review, 62(3), 323-336. Retrieved from http://her.hepg.org/content

Weinberger, C.J. (2005). Is the Science and Engineering Workforce Drawn from the Far Upper Tail of the Math Ability Distribution? Institute for Social, Behavioral and Economic Research and Department of Economics University of California Santa Barbara. Retrieved from http://www.econ.ucsb.edu/ weinberg/uppertail.pdf.

White, S. \& Tesfaye. C.L. (2010). Who teaches high school physics? Focus On. College Park, MD. Retrieved from http://www.aip.org/statistics/trends/reports/hsteachers/pdf

-----. (2011, January). Female students in high school physics. Focus On. College Park MD. Retrieved from http://www.aip.org/statistics/trends/reports/females.pdf. 


\section{LAGGING BEHIND}

Whitten, B.L., Foster, S.R., \& Duncombe, M.L. (2003, September). What works for women in undergraduate physics? Physics Today, 56(9), 46. Retrieved from http://aas.org/cswa/status/2005/January2005/WhatWorksForWomen.html.

Zeldin, A.L., \& Pajares, F. (2000). Against the odds: Self-efficacy beliefs of women in mathematical, scientific, and technological careers. American Educational Research Journal, 37(1), 215-246. 


\section{LAGGING BEHIND}

Appendix A

Parental Consent Form

My child has permission to participate in a survey being conducted by Elisabeth A. Myers in order to complete her research project on factors affecting the pursuit of a college physics degree. I understand that all students' identities will be kept confidential in the presentation of the material.

Parent/guardian signature

Date 


\section{LAGGING BEHIND}

Appendix B

Science Survey

Please answer all questions which apply to you. If a question does not apply, skip it.

Name Date

Grade level

\section{A. Demographics}

1. Which grade levels have you attended at GCCS?

2. If you attended a different school previously, please name it.

3. Which grade levels did you attend in your previous school?

4. Have you ever been homeschooled?

5. For which grade levels were you homeschooled?

\section{B. Science and Math Classroom Background}

6. Check each one of the classes listed below which you have completed or a currently enrolled in.

_ IPS (Introduction to Physical Science)

Biology

Chemistry or ___ Chemistry Concepts

Physics or Conceptual Physics
Algebra I

Geometry

Algebra II

Pre-Calculus

Bio II Genetics Anatomy \& Physiology Calculus 


\section{LAGGING BEHIND}

7. List any other science or math course you have taken for high school credit, include AP courses.

8. In general, are you an A, A/B, B, B/C, C, or D/below science student?

9. In general, are you an A, A/B, B, B/C, C, or D/below math student?

\section{Potential College Plans}

10. Circle all areas of study you would feel confident enough in your ability to pursue a major in at college.

\section{Biology Chemistry Engineering Math Physics Not listed}

11. Circle all areas of study in which you would be interested in pursuing a major in at college.

Biology Chemistry Engineering Math Physics Not listed

12. If you were not interested in majoring in any of the following please briefly, but as specifically as you can, explain why not.

a. Biology

b. Chemistry

c. Engineering 


\section{LAGGING BEHIND}

d. Math

f. Physics

13. If you have specific college or career plans please describe them.

\section{Other Science Experiences}

14. Have you participated in any hobbies, camps, or clubs which are science or math related ( robotics, $4 \mathrm{H}$, etc.)? Describe them.

15. a. Did you participate in our Junior Science Challenge Day this past fall?

b. Describe the aspects of this day which you enjoyed most, hands-on approach, problem solving, design and test, competition, etc.

c. Did the Junior Science Day Challenge increase your interest in physics? Please comment.

d. What could be done to increase your interest in physics? 


\section{LAGGING BEHIND}

Appendix C

GCCS Science Challenge Day 2011

Challenge One $=$ The Egg Drop Challenge

The challenge is to build an encasement for a raw egg that will protect it from cracking or breaking when dropped from 20+ feet (balcony in the Food Court).

- The encasement must not be larger than a shoe box.

- At least $1 / 4^{\text {th }}$ of the egg must be visible.

- You may only use the provided materials. (Bag of supplies, 1 meter of tape + scissors)

- You must be able to show/remove the entire egg after the drop without destroying your encasement.

- You will be allowed one raw egg for testing purposes as you construct your project. Test will be conducted from a lesser height in your assigned classroom.

Timeline:

8:00 Breakfast (in classroom)

8:10 Announcements, Pledge, and Prayer

8:15 Introduction, Directions, \& Consideration for Challenge 1 (Room Assignment)

8:25ish to 9:42 Plan, Experiment and Build encasement

9:42 Clean up classroom

9:45 Head down to Josiah’s Café (Food Court Balcony) to Test encasement \& Clean up

10:25ish Head back to Cafeteria for lunch 


\section{LAGGING BEHIND}

LUNCH: 10:33 - 11:05

Challenge Two $=$ The Maneuverable Mobile Vehicle Building Challenge

The Challenge is to build a vehicle that will travel 10 meters as quickly as possible without being touched. It cannot be thrown, projected, or pushed/pulled.

The vehicle must have contact with the ground. The winner of this competition will be determined by multiple races with other vehicles. You are only allowed to use the provided bag of supplies, 1 meter of tape and scissors.

Timeline:

11:10 Introduction, Directions, \& Considerations for Challenge 2 (Room Assignment)

11:12ish - 12:42 Plan, Experiment, \& Build Vehicles

12:42 Clean up room

12:45 To Gym for Vehicle Trials

12:47 - 1:38 Vehicle Trials

1:38 - 1:45 Bathroom Break

1:45 Head to Church Choir Room

1:50 Refreshments

2:00 Guest Speaker: Female ODOT Engineer

2:30ish Discussion and Survey 